\title{
Perilaku kekasaran permukaan baja AISI 1045 terhadap kekerasan dan laju korosi serta daya lekat permukaan hasil elektroplating
}

\author{
Sunardi $^{\star}$, Slamet Wiyono${ }^{2}$, Dhimas Satria ${ }^{3}$, Rina Lusiani ${ }^{4}$, Erny Listijorini ${ }^{5}$, Wira \\ Pratama $^{6}$
}

\author{
1,2,3,4,5,6 Jurusan Teknik Mesin, Universitas Sultan Ageng Tirtayasa \\ Jl. Jendral Sudirman KM 03 Cilegon - Indonesia 42435 \\ ${ }^{*}$ Corresponding author: sunardi@untirta.ac.id
}

\begin{abstract}
Electroplating is the coating metals with thin layers of other metals by electrolysis to improve the surface properties of materials, especially corrosion resistance. Electroplating is widely used in the automotive, electronics, medical, aerospace, gas, and oil industries. This study will discuss the effect of substrate surface roughness of AISI 1045 steel toward surface roughness, hardness, corrosion rate, and bonding strength of the coating. The surface roughness of the substrate is obtained by grinding process using sandpaper with grades 80, 320, and 1000. In this study, the coating material is Chromium. The electroplating parameters used in this research are 5-volt voltage, current 500 Amperes, and the time of 15 minutes. From this research, it is known that the surface roughness of the substrate material has an influence on the quality of the coating. The lower the surface roughness, improve the roughness, hardness, corrosion rate, and bonding strength.
\end{abstract}

Keywords: electroplating, surface roughness, hardness, corrosion rate, bonding strength.

\begin{abstract}
Abstrak
Elektroplating adalah pelapisan logam dengan lapisan tipis logam lain melalui proses elektrolisis dengan tujuan untuk memperbaiki sifat permukaan material, terutama ketahanan korosinya. Elektroplating banyak digunakan di industri otomotif, elektronik, medis, aerospace, industri gas dan minyak. Pada paper ini akan dibahas perilaku kekasaran permukaan substrat baja AISI 1045 terhadap kekasaran, kekerasan, laju korosi dan daya ikat permukaan lapisan. Kekasaran permukaan substrat diperoleh melalui proses grinding yang menggunakan amplas dengan grade 80, 320, dan 1000. Dalam penelitian ini pelapis yang digunakan adalah Chromium. Parameter elektroplating yang digunakan adalah tegangan 5 volt, arus 500 ampere dan waktu 15 menit. Dari riset ini diketahui bahwa kekasaran permukaan substrat memiliki pengaruh terhadap kualitas hasil pelapisan. Semakin rendah kekasaran permukaan maka kekarasan, daya ikat dan laju korosinya semakin baik.
\end{abstract}

Kata kunci: Elektroplating, kekasaran permukaan, kekerasan, laju korosi, daya lekat.

\section{Pendahuluan}

Pencegahan kerusakan permukaan material logam dapat dilakukan dengan pengecatan maupun pelapisan. Pelapisan logam merupakan metode yang paling banyak digunakan dan memiliki jenis yang beragam, seperti galvanisasi, elektroplating hingga thermal spray. Penelitian yang dilakukan untuk merekayasa ketahanan material terhadap serangan korosi atau tujuan dekoratif lainnya sudah dilakukan dari masa ke masa seiring dengan perkembangan ilmu pengetahuan dan teknologi.

Jenis pelapisan yang digunakan dalam penelitian ini adalah elektroplating. Prinsip elektroplating adalah dengan jalan mengendapkan ion-ion lapisan pelapis ke dalam material yang dilapisi melalui proses elektrokimia. Dalam penelitian ini akan dibahas pengaruh kekasaran permukaan substrat terhadap kualitas 
lapisan permukaan. Yang dimaksud kualitas dalam riset ini adalah kekasaran, kekerasan, laju korosi, dan daya lekat antar permukaan.

\section{Tinjauan Pustaka}

Salah satu parameter thermal spray yang cukup berpengaruh terhadap pelapisan material Baja AISI 3115 dengan baja tahan karat 316 adalah arus listrik yang digunakan. Semakin tinggi arus listrik yang digunakan maka kekerasan, ketahanan korosi dan daya lekat antar permukaan menjadi lebih baik [1]. Perlakuan awal dengan memanaskan material substrat juga memiliki pengaruh terhadap kualitas lapisan. Pemanasan material substrat pada suhu $90^{\circ} \mathrm{C}$ memberikan karakteristik daya lekat, kekerasan, dan densitas permukaan lapisan yang lebih baik jika dibandingkan pada suhu yang lebih tinggi [2].

Preparasi material dilakukan dengan tujuan menghilangkan kontaminan yang dapat menyebabkan penurunan ikatan antar permukaan sehingga daya lekat menjadi buruk. Langkah ini biasanya meliputi pembersihan, perlakuan, dan pembilasan. Pembersihan biasanya dilakukan dengan menggunakan larutan tertentu seperti alkali, air ataupun asam untuk melepaskan minyak yang melekat pada permukaan substrat. Pembersihan dapat juga dilakukan dengan larutan bahan kimia aktif, penyikatan maupun agitasi ultrasonik.

Ukuran partikel dan nilai kekasaran permukaan film magnetit pada proses electrodeposition menurun seiring dengan menurunnya kekasaran permukaan substrat, sedangkan ketebalan dan kekasaran permukaan film magnetit meningkat secara signifikan seiring dengan peningkatan kecepatan agitasinya[3]. Kekasaran dan ukuran kristal hasil proses dicalcium phosphate dehydrate meningkat seiring dengan bertambahnya densitas arus pelapisan. Laju korosi yang paling baik terjadi pada densitas arus $0,4 \mathrm{~mA} / \mathrm{cm}^{2}$ selama 60 menit [4].
Pengendapan partikel $\alpha-\mathrm{Al}_{2} \mathrm{O}_{3}$ ke dalam matriks nikel dapat memberikan dampak penghalusan ukuran butiran nikel, sehingga dapat meningkatkan koefisien gesek, kekerasan mikro dan ketahanan aus [5]. Pembentukan lapisan nanocomposite $\mathrm{Ni}-\mathrm{Al}_{2} \mathrm{O}_{3}$ pada proses electrodeposition dapat memperbaiki sifat ketahanan aus material. Faktor yang paling berpengaruh terhadap kualitas lapisan pada proses ini adalah konsentrasi partikel, kemudian diikuti oleh suhu dan densitas arus [6].

Proses elektroplating adalah proses pelapisan logam pada logam lain dengan cara elektrolisis. Beberapa faktor yang berpengaruh terhadap kualitas lapisan, antara lain: $\mathrm{pH}$, suhu, current density, waktu, ukuran partikel, jenis partikel, jenis surfaktan, konsentrasi larutan dan agitasi [7], [8]. Pemilihan logam pelapis dan jenis elektrolit sangat menentukan kualitas pelapisan. Larutan elektrolit yang digunakan dapat berupa asam, basa maupun garam tergantung tujuan utama, apakah untuk ketahanan korosi, reflektifitas, kekerasan, kekuatan mekanik, keuletan dan ketahanan aus.

Durasi pelapisan memiliki pengaruh yang signifikan terhadap kualitas lapisan. Ketebalan, kekerasan, dan kekasaran permukaan lapisan film okside meningkat seiring dengan naiknya waktu pelapisan [9]. Kekuatan lelah material baja AISI 1039 yang dilapisi oleh hard chromium mengalami penurunan. Hal ini disebabkan adanya tegangan sisa berupa tarik yang menjadi inisiasi retakan. Ketebalan lapisan meningkat seiring dengan naiknya waktu pelapisan. Ketebalan lapisan maksimum yang dapat dicapai adalah $33 \mu \mathrm{m}$ pada waktu pelapisan selama 30 menit serta memberikan kekasaran permukaan yang lebih halus [10].

Daya lekat antar permukaan pada proses pelapisan nirelektrik dapat ditingkatkan dengan pembentukan lapisan Ni-P dan merekaya kekasaran permukaan substrat [11]. Semakin tinggi kekasaran permukaan pada proses pelapisan 
nirelektrik Ni-P maka daya lekat antar lapisan semakin tinggi. Di sisi yang lain, kecepatan agitasi berpengaruh secara linier terhadap ukuran partikel lapisan dan ketebalan lapisan yang terbentuk [12][13].

Kekerasan mikro dan ketahanan aus material dapat ditingkatkan dengan pembentukan lapisan komposit $\left(\mathrm{Ni}-\mathrm{Al}_{2} \mathrm{O}_{3}\right.$, $\mathrm{Ni}-\mathrm{SiC}$ dan $\mathrm{Ni}-\mathrm{ZrO}_{2}$. Dari ketiga lapisan tersebut maka komposit $\mathrm{Ni}-\mathrm{Al}_{2} \mathrm{O}_{3}$ memberikan dampak paling baik karena adanya kandungan $\mathrm{Al}_{2} \mathrm{O}_{3}[14][15]$.

\section{Metode Penelitian}

Material yang digunakan adalah baja AISI 1045 dengan diameter $25 \mathrm{~mm}$ dan panjang $25 \mathrm{~mm}$. Untuk memperoleh kekasaran permukaan yang bervariasi adalah dengan melakukan grinding dengan amplas grade 80, 320, dan 1000. Parameter proses elektroplating menggunakan tegangan listrik $5 \mathrm{~V}$, arus 500 Ampere dan waktu pelapisan 15 menit.

Karakteristik lapisan Chromium yang terbentuk ditentukan berdasarkan kekasaran, kekerasan lapisan, kekuatan daya ikat dan laju korosi permukaan material. Pengujian kekasaran permukaan dilakukan dengan Perthometer Digital. Penentuan kekerasan lapisan chromium menggunakan micro vicker hardness, dimana indentor yang digunakan berbentuk piramida intan dengan sudut $136^{\circ}$. Laju korosi lapisan permukaan chromium dilakukan dengan larutan $\mathrm{NaCl}$ 2M. Pengujian daya lekat antar permukaan substrat dan lapisan chromium dilakukan dengan UTM (universal testing machine).

\section{Hasil dan Pembahasan}

Pembahasan karakteristik material hasil elektroplating akan diuraikan dalam penjelasan berikut ini.

\section{Kekasaran Permukaan}

Pengukuran kekasaran permukaan Baja AISI 1045 sebelum dan sesudah proses pelapisan menggunakan Perthometer Digital di Laboratorium Kalibrasi PT. Krakatau Steel Divisi CRM.
Kekasaran permukaan merupakan ketidateraturan suatu permukaan berupa goresan atau lekuk-lekuk kecil hasil proses manufaktur.

Kekasaran lapisan chromium sangat ditentukan oleh kekasaran permukaan substrat. Dari Gambar 1 dapat diketahui bahwa kekasaran permukaan lapisan linier terhadap kekasaran material subsrat dan meningkat seiring dengan peningkatan kekasaran permukaan lapisan substrat. Hal ini disebabkan oleh endapan yang terbentuk mengikuti kontur material substrat.

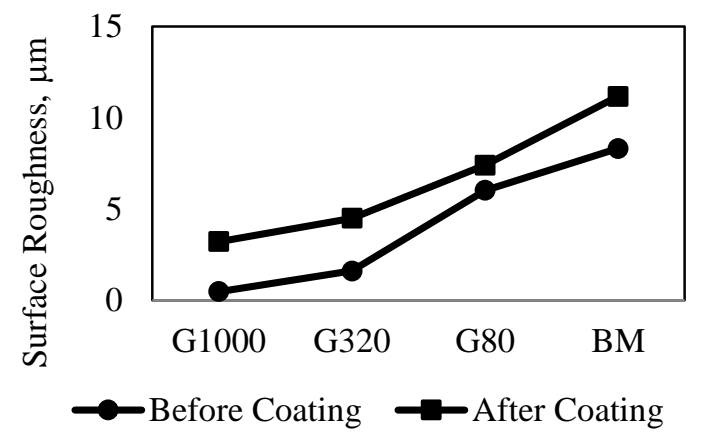

Gambar 1. Perbedaan tingkat kekasaran sebelum dan sesudah coating

\section{Kekerasan Permukaan Lapisan}

Kekerasan lapisan chromium memiliki korelasi dengan kekasaran permukaan substrat. Hal ini disebabkan oleh kontur permukaan yang kasar biasanya memiliki porositas yang tinggi sehingga indentor dapat dengan mudah terdeformasi pada lapisan chromium. Dengan demikian injakan indentor akan semakin dalam. Dari grafik terlihat bahwa semakin tinggi kekasaran permukaan maka semakin rendah kekerasannya.

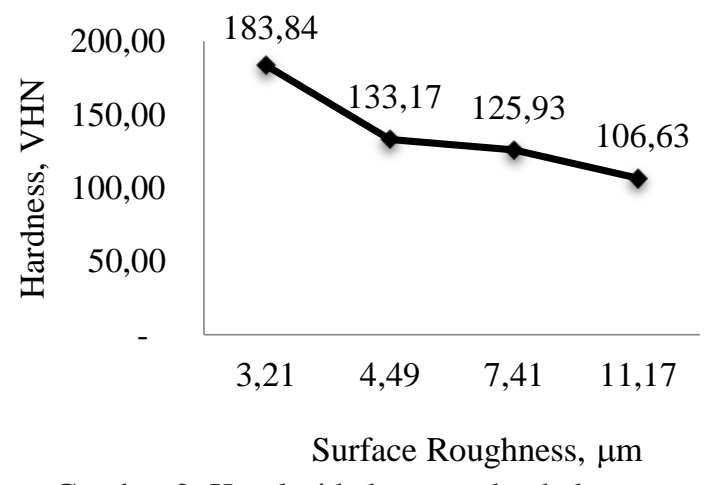

Gambar 2. Korelasi kekasaran dan kekerasan permukaan lapisan 


\section{Hasil Uji Korosi}

Pengujian laju korosi pada lapisan chromium dilakukan dengan menggunakan larutan $\mathrm{NaCl}$. Dari Gambar 3 diketahui bahwa kekasaran lapisan berkorelasi kuat dengan laju korosi yang terjadi. Laju korosi meningkat seiring dengan naiknya kekasaran permukaan lapisan Chromium.

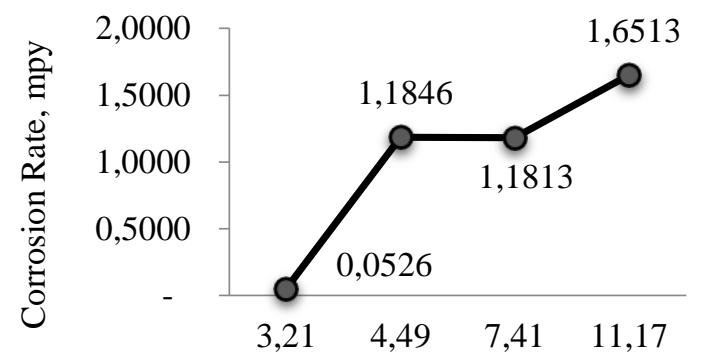

Surface Roughness, $\mu \mathrm{m}$

Gambar 3. Korelasi antara kekasaran dan laju korosi pada lapisan

Laju korosi yang tinggi pada permukaan yang lebih kasar disebabkan oleh semakin tingginya kontak permukaan dengan udara luar. Besarnya kontak ini memiliki potensi yang lebih besar terjadi oksidasi oleh udara atau lingkungan korosif lainnya. Sedangkan pada permukaan yang lebih halus memiliki kecenderungan lebih rendah laju korosinya. Hal ini disebabkan oleh luas kontak lapisan teroksidasi lebih kecil, di samping itu porositas kekasaran permukaan yang lebih halus juga relatif kecil.

\section{Daya Lekat Permukaan}

Pengujian daya lekat lapisan chromium dilakukan dengan mengikuti standar ASTM C 633-79. Daya lekat antar permukaan dipengaruhi oleh perlakuan awal dan kekasaran permukaan material substrat. Kekasaran substrat yang tinggi dapat menyebabkan terjebaknya udara oleh proses pelapisan. Udara terjebak ini dapat membentuk microvoid yang akan menjadi initial cracking antar permukaan.

Kekasaran permukaan yang sangat halus hingga angka tertentu nyaris tidak memiliki dampak yang signifikan terhadap daya lekatnya. Perubahan cukup mencolok terjadi pada kekasaran permukaan 8.32 $\mu \mathrm{m}$, dimana terjadi penurunan daya lekat antar permukaan hingga $26 \%$.

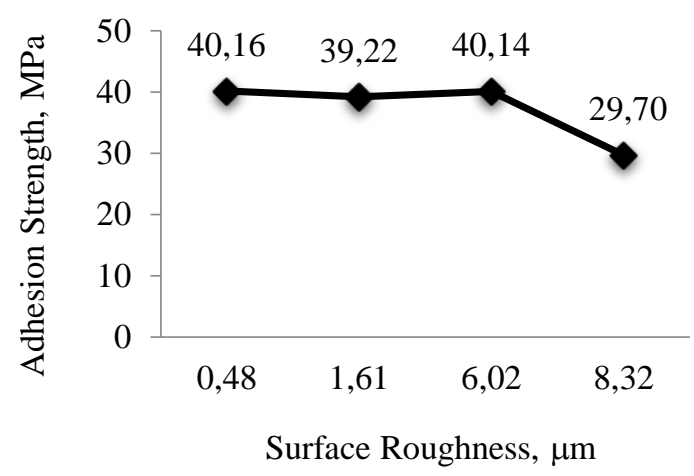

Gambar 4. Korelasi antara kekasaran permukaan dan daya lekat

Permukaan substrat yang halus lebih memiliki daya lekat antar partikel yang lebih merata. Kedalaman difusi atom chromium ke permukaan substrat lebih merata sehingga akan menghasilkan kekuatan ikatan antara permukaan substrat dan lapisan tipis chromium yang lebih tinggi. Kekuatan ikatan pada kekasaran permukaan hingga $6.02 \mu \mathrm{m}$ memiliki perbedaan yang relatif kecil, yaitu $2.34 \%$.

5. Hubungan kekerasan terhadapKorosi

Kekerasan merupakan kemampuan logam untuk menahan terjadinya deformasi atau pergeseran. Korosi adalah kerusakan material yang disebabkan karena reaksi material dengan lingkungan sekitarnya. Hubungan antara kekerasan dan laju korosi ditunjukkan oleh Gambar 5 .

Kekerasan permukaan lapisan dapat mempengaruhi perilaku korosi sebuah material. Semakin tinggi kekerasan lapisan maka laju korosinya semakin rendah. Hal ini dapat dimengerti karena kekerasan yang lebih tinggi memiliki porositas yang lebih rendah, sehingga udara yang teroksidasi di lapisan chromium menjadi berkurang. Porositas yang terbentuk pada permukaan lapisan dapat menjadi inisiasi terjadinya korosi sumuran. 


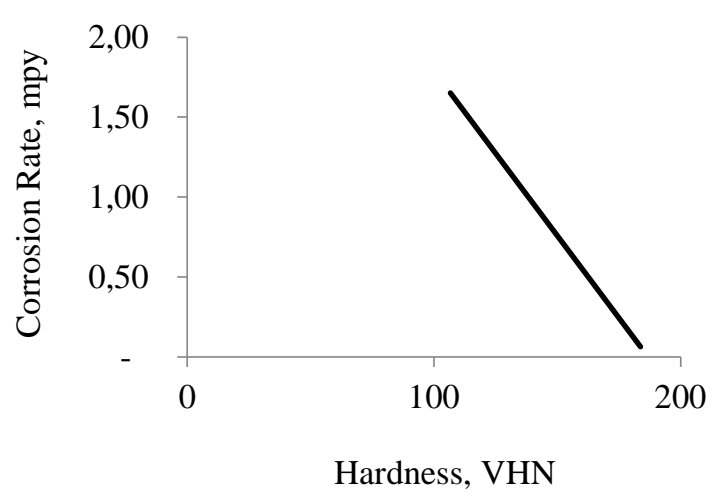

Gambar 5. Korelasi antara kekerasan permukaan dan laju korosi

\section{Kesimpulan}

Kekasaran permukaan substrat baja AISI 1045 pada proses elektroplating berpengaruh terhadap kekasaran, kekerasan, laju korosi dan daya lekat lapisan. Semakin tinggi kekasaran lapisan maka semakin tinggi kekerasan lapisan dan laju korosinya. Kekasaran permukaan tidak signifikan berpengaruh terhadap perubahan daya lekat permukaan.

\section{Ucapan Terimakasih}

Pada kesempatan ini, penulis mengucapkan terimakasih kepada Fakultas Teknik Universitas Sultan Ageng Tirtayasa yang telah membiayai penelitian ini. Terimakasih juga disampaikan kepada PT. Krakatau Steel dan Pusat Penelitian LIPI atas kontribusinya dalam karakterisasi material.

\section{Referensi}

[1] R. Lusiani, Sunardi, and Hamidi, "Sifat Mekanik Lapisan Stainless Steel 316 pada Baja Karbon Rendah dengan Proses Electric Arc Spray," in Seminar Nasional Industrial Services (SNIS III), 2015, pp. 429434.

[2] Sunardi, Erwin, and R. R. Ramadhan, "Karakteristik Lapisan METCO 404NS dengan Variasi Pemanasan Awal Material Substrat pada Proses Thermal Spray," in Seminar Nasional Teknologi Manufaktur, 2014, pp. 123-128.
[3] S.-H. Jeon, W.-I. Choi, G.-D. Song, Y.-H. Son, and D. H. Hur, "Influence of Surface Roughness and Agitation on the Morphology of Magnetite Films Electrodeposited on Carbon Steel Substrate," Coating, vol. 6, no. 62, pp. 1-12, 2016.

[4] H. R. Bakhsheshi-rad, E. Hamzah, and S. N. Saud, "Effect of Electrodeposition Parameters on the Microstructure and Corrosion Behavior of DCPD Coatings on Biodegradable $\mathrm{Mg}-\mathrm{Ca}-\mathrm{Zn}$ Alloy," Int. J. Appl. Ceram. Tecnol., vol. 11, pp. 1-11, 2014.

[5] A. Goral, L. Litynska-Dobrzyska, and M. Kot, "Effect of Surface Roughness and Structure Features on Tribological Properties of Electrodeposited Nanocrystalline Ni and Ni/A12O3 Coatings," J. Mater. Eng. Perform., 2017.

[6] C. R. Raghavendra, S. Basavarajappa, and I. Sogalad, "Study on Influence of Surface roughness of $\mathrm{Ni}^{-} \mathrm{Al} 2 \mathrm{O} 3$ Nano Composite Coating and Evaluation of Wear Characteristics," in IOP Conference Series: Materials Science and Engineering 310, 2018, pp. 1-9.

[7] S. Kumar, S. Pande, and P. Verma, "Factor Effecting Electro-Deposition Process," Int. J. Curr. Eng. Technol., vol. 5, no. 2, pp. 700-703, 2015.

[8] E. S. Güler, "Effects of Electroplating Characteristics on the Coating Properties," Electrodepos. Compos. Mater. coatings, no. March 2016, pp. 27-37, 2017.

[9] A. Taherkhani, Y. Shajari, K. Mirzavand, A. Mellatkhah, and Z. S. Seyedraoufi, "The Effect of Electroplating Time on Microstructural Properties and Hardness of Silver Coating on C10100 Alloy," J. Environ. Friendly Mater., vol. 3, no. 2, pp. 5-9, 2019.

[10] Z. D. Kadhim, M. A. Abdulrazzaq, and Z. N. Jassim, "Effect of Coated 
Layer of Hard Chromium on Fatigue Behavior for AISI 1039 Medium Carbon Steel," J. Eng. Sustain. Dev., vol. 22, no. 2, pp. 72-85, 2018.

[11] S. H. Bae, S. Kim, S. H. Yi, I. Son, K. T. Kim, and H. Chung, "Effect of Surface Roughness and Electroless $\mathrm{Ni}$ - P Plating on the Bonding Strength of $\mathrm{Bi}-$ Te-based Thermoelectric Modules," Coating, vol. 9, no. 213, pp. 2-9, 2019.

[12] R. D. Rachmani, A. Nikitasari, Sunardi, and E. Mabruri, "Pengaruh Kekasaran Permukaan dan Kecepatan Pengadukan terhadap Karakteristik Lapisan Nirelektrik Ni$\mathrm{P}$ pada Baja Tahan Karat Martensitik," Widyariset, vol. 4, no. 1, pp. 21-28, 2018.

[13] Permadi, B., Asroni, A., \& Budiyanto, E. (2019). Proses elektroplating nikel dengan variasi jarak anoda katoda dan tegangan listrik pada baja ST-41. Turbo: Jurnal Program Studi Teknik Mesin, 8(2).

[14] T. Borkar and S. P. Harimkar, "Effect of Electrodeposition Conditions and Reinforcement Content on Microstructure and Tribological Properties of Nickel Composite Coatings," Surf. Coat. Technol., vol. 205, pp. 4124-4134, 2011.

[15] Budiyanto, E., Setiawan, D. A., Supriadi, H., \& Ridhuan, K. (2017). Pengaruh jarak anoda-katoda pada proses elektroplating tembaga terhadap ketebalan lapisan dan efisiensi katoda baja AISI 1020. Turbo: Jurnal Program Studi Teknik Mesin, 5(1). 